\title{
Improvement Strategies for Manufacturers Using the MESA MOM Capability Maturity Model
}

\author{
Quanri $\mathrm{Li}^{1}$, Michael Brundage ${ }^{1}$, Boonserm (Serm) Kulvatunyou ${ }^{1}$, Dennis Brandl ${ }^{2}$, and \\ Sang Do $\mathrm{Noh}^{3}$ \\ ${ }^{1}$ Systems Integration Division, National Institute of Standards and Technologies \\ \{quanri.li,michael.brundage,serm\}@nist.gov \\ ${ }^{2} \mathrm{BR} \& \mathrm{~L}$ Consulting, LLC \\ dnbrandl@brlconsulting.com \\ ${ }^{3}$ Department of Systems Management Engineering, Sungkyunkwan University \\ sdnoh@skku.edu
}

\begin{abstract}
Recently, the concept of smart manufacturing has emerged as a new paradigm, with which manufacturers can enhance their competitiveness in the market. Smart manufacturing paradigm can be viewed as the convergence of Information \& Communication Technologies with human capabilities and manufacturing technologies. The new paradigm is expected to bring a new wave of performance improvements to manufacturing industries. However, manufacturing enterprises need to expend significant effort when preparing to adopt new technologies and realize their full benefits. MESA (Manufacturing Enterprise Systems Association) created the Manufacturing Operations Management/Capability Maturity Model (MOM/CMM) to help evaluate the maturity and readiness of manufacturing enterprises from the factory operations perspective. However, the model, in its raw form, can be time- and resourceconsuming. It also lacks improvement strategies that use results of evaluation. The objective of this work is to restructure the questionnaire to reduce its completion time and to outline strategies through which a manufacturing enterprise can derive its improvement plans.
\end{abstract}

Keywords: Smart manufacturing, Manufacturing operations management, Maturity model, Readiness assessment, Improvement strategies

\section{Introduction}

As the global competition in the manufacturing industry becomes more intense, a large number of new technologies, both hardware and software solutions, are being developed and applied in the industry. As a result, the concept of smart manufacturing has emerged as a new paradigm that is expected to lead to innovations across many industries. To implement the new paradigm across various manufacturing industries, research efforts are being carried out throughout the world under governmental projects such as NNMI (National Network for Manufacturing Innovation, USA), Industrie 4.0 (Germany), Horizon 2020: Factories of Future (EU), etc., aimed at 
bringing innovations to manufacturing processes, productivity improvements, and increased quality of products [1].

However, often times, manufacturing enterprises cannot fully benefit from these technologies unless they have achieved a certain level of maturity in their manufacturing operations [2]. For example, if there is no procedure established for production tracking, manufacturers are not able to select and locate necessary sensors in their manufacturing systems. A method is needed for evaluating foundational capabilities that support repeatable daily manufacturing operations and continuous performance improvements along with a guideline to help manufacturers increase their readiness for adopting the emerging smart manufacturing technologies.

In our previous work, we developed the Smart Manufacturing System Readiness Assessment (SMSRA) method that measures the maturities of the information connectivity, organization, performance management, and IT system, all of which are important components for deploying new Information \& Communication Technologies (ICTs) in a manufacturing system from the shop floor level to the enterprise level [3]. Manufacturing Enterprise Systems Association (MESA) Manufacturing Operation Management Capability Maturity Model (MOM/CMM), on the other hand, provides a method for evaluating the foundational capabilities that should be in place before or while adopting ICTs, particularly at the shop floor level [4]. The model is based on the activity models that are defined in the ISA-95 Part 3 [5]. Although some overlaps exist, MOM/CMM can be viewed as a precursor to the SMSRA. In other words, a factory should already be at level 4 or level 5 of the $\mathrm{MOM} / \mathrm{CMM}$ before applying the SMSRA.

NIST is working with MESA to pilot the MOM/CMM with manufacturers; however, feedback from an initial discussion with potential pilot participants provides the following conclusions: 1) providing answers to all 832 questions of the complete $\mathrm{MOM} / \mathrm{CMM}$ questionnaire (or even a subset of the questionnaire for a single operational area) to evaluate the maturity is too time-consuming; and 2) there is no clear direction to how a manufacturing organization can derive improvement plans based on the evaluation result.

In this paper, we present the result of our work to reduce the effort needed to complete the questionnaire and provide an initial guideline for manufacturers to derive an improvement strategy based on the evaluation result.

\section{Overview of MESA MOM/CMM}

Part 1 of ISA-95 defines five hierarchical levels ( 0 to 4$)$ for processes and systems that make up a manufacturing enterprise system $[6,7]$. The MESA MOM/CMM is defined based on level 3 processes - the manufacturing operations management (MOM) processes. Four operational areas are defined at level 3: production operations management, quality operations management, inventory operations management and maintenance operations management. Each operational area consists of a set of activities related to detailed scheduling, dispatching, execution 
management, resource management, definition management, data collection, tracking and performance analysis [5].

The maturity level is measured by answering "yes/no" to the questionnaire that is organized per activity [5]. Each activity can have the maturity level 0 to level 5. See Table 1 for example questions at each maturity level (within the actual questionnaire, each maturity level may have up to 9 questions). The maturity levels are defined as follows:

Level 0: There has been no evaluation performed.

Level 1: The processes are at initial stage and not documented or formally managed.

Level 2: Some of the processes are repeatable with possibly consistent results and documented.

Level 3: The processes are defined with documented standards for all activities.

Level 4: The processes are defined and documented across all organizational groups.

Level 5: The processes focus on continuous improvement and optimization.

Beside evaluating the maturity from the activity viewpoint, the questions can also be organized and evaluated with respect to 7 aspects namely roles and responsibility, succession plans and backups, policies and procedures, technology and tools, training, information integration and KPI. This will be addressed in our future work.

\section{$3 \quad$ Related works}

Numerous frameworks or models for maturity assessment and/or evaluation of business or processes exist in various industries. A maturity model serves as a means for assessing and providing an improvement framework. The Capability Maturity Model (CMM) is a software engineering process improvement model developed by Software Engineering Institute (SEI) at Carnegie Melon University, which triggered surge of development of maturity models in diverse fields [8].

One of the first maturity models developed is the Quality Management Maturity Grid (QMMG) by Philip B. Crosby in 1979 [9]. It evaluates the maturity of the organization's service and product quality management processes and how organizational cultures are affected by those processes.

In the field of supply chain management, SCRL-Model (Supply Chain Readiness Level) is a well-defined maturity evaluation model. The model is designed to evaluate supply chain maturity by answering assessment questions in various sections such as inventory, supplier consolidation, supplier/customer relationships, commodity price adaptability, visibility etc. By doing so, a SCRL number is assigned to each section and it yields a level that indicates the maturity of the supply chain and how well it has been prepared. The goal of the model is to increase operational efficiency by identifying and mitigating operational risks in the supply chain. [10]

While the SCRL-Model serves as an assessment tool for the supply chain management field, the Manufacturing Readiness Level has been developed by the US 
Department of Defense (DoD) for the manufacturing field. According to [11], the MRL defines the current level of manufacturing maturity along with elements such as cost and risks that affect the manufacturing processes.

The models introduced thus far (i.e., QMMG, SCRL-Model, MRL) assess the processes or practices in one dimension with associated questions for each level. However, MESA MOM/CMM consists of multi-dimensional questions to evaluate the maturity levels of activities in manufacturing operations and from varied aspects at the same time. Hence, the MESA approach to assessment is different from the aforementioned models.

Putting the number of dimensions covered by MESA MOM/CMM aside, an investigation on design of questionnaire is a primary concern since MESA MOM/CMM consists of series of 832 questions. According to [12], the number of questions in a questionnaire affects the quality of answers to the questionnaires. Specifically, the rate of response to the questionnaire could be increased by reducing the number of questions. Also, to reduce cognitive load on respondents, it is recommended to have a maximum of 20 words per sentence. However, one question can consist of more than one sentence [12]. Also, questions that are worded in negative tones tend to have greater cognitive load on respondents due to longer time required for their processing. It is recommended to have questions worded in positive tones as often as possible [13]. In the next section, we discuss our work to improve MESA MOM/CMM questionnaire due to these research findings and the initial feedback described in section 1 .

\section{Restructure of MESA MOM/CMM}

Currently, MESA MOM/CMM consists of 832 yes/no questions across 4 operational areas, each of which has 8 activities to evaluate maturity, effectiveness, robustness and repeatability of the manufacturing operations and practices. The MESA MOM/CMM can be treated as a benchmark for comparison between different operational areas and activities. However, parsing through and answering all 832 questions can be a daunting task.

One strategy to address this issue is to select a subset of operational areas and activities to focus on beforehand so that only a relevant subset of 832 questions is answered at one point in time. However, this approach does not save time and effort as manufacturers may not be able to decide how to prioritize operational areas or subsets. Furthermore, having a complete picture of the entire operation would allow a better investment decision to be made.

Alternatively, restructuring the questionnaire to reduce the number of questions and words while retaining the original intent of the questionnaire is pursued. The following techniques are used in the restructuring process:

1) Questions that are composite are decomposed into multiple questions. Composite questions are ambiguous to the interviewee when only one part of the question is true. This improves the clarity and answerability of the question. 
2) Questions at all levels under a single activity are first grouped according to overlapping keywords and then converted into multiple choice questions. This reduces the number of questions and words the interviewee must parse.

Table 1 shows example questions for the 'detailed production scheduling' activity within the 'production operations management' operational area. In the table, the keyword "procedure" for detailed production scheduling appears repetitively at level 1 to 3. Similar repetitions exist throughout the questionnaire. These questions can be grouped together based on those repeated keywords and be restructured into a multiple-choice question.

Table 2 shows an example of the restructured questionnaire. Notice that the question is no longer structured per maturity level, it rather aggregates across levels. A programmatic mapping has been developed such that the answer to the new representation of the question is automatically mapped to the original question and the maturity level can be automatically calculated.

Table 1. Example of repeated questions

\begin{tabular}{|c|l|}
\hline $\begin{array}{c}\text { Leve } \\
1\end{array}$ & Question \\
\hline 1 & $\begin{array}{l}\text { There are no defined procedures for Detailed Production Scheduling and } \\
\text { the processes are not repeatable during times of stress. }\end{array}$ \\
\hline 2 & $\begin{array}{l}\text { Detailed Production Scheduling processes vary across organizational } \\
\text { groups, with different processes and procedures used in different groups. }\end{array}$ \\
\hline 3 & $\begin{array}{l}\text { Detailed Production Scheduling processes are defined across all } \\
\text { organizational groups, and the organization follows written and controlled } \\
\text { policies. }\end{array}$ \\
\hline 4 & (All Level 3 processes are in place.) \\
\hline 5 & (All Level 4 processes are in place.) \\
\hline
\end{tabular}

We have restructured questions in 2 activities under 1 operational area. The result is promising, the number of questions was reduced to 14 from 29 , and the number of words was reduced approximately by $47 \%$ (from 473 words to 248 words) in each activity.

Table 2. Example of grouped questions

\begin{tabular}{|c|l|}
\hline Choice Question & Procedures for Detailed Production Scheduling \\
\hline A & Not defined \\
\hline B & Defined, but vary across organizational groups \\
\hline C & Defined across all organizational groups \\
\hline
\end{tabular}

\section{Improvement strategies}


Since the evaluation work is time-consuming and labor-intensive, there should be a strategic and efficient approach to evaluations. Once an enterprise decides to evaluate its current status of maturity, it can choose an improvement strategy between the three different types as shown in Table 3: vertical improvement, horizontal improvement and hybrid improvement.

Vertical improvement strategy focuses on achieving high maturity levels across activities that are high priority, one operational area at a time. This strategy can work well with manufacturers that know the particular operational area on which they would like to focus their improvement. If such a decision can be made early, the manufacturers can also address the maturity assessment one operation at a time as well. Another advantage of this strategy is that it can result in high initial ROI (Return of Investment) compared to other strategies because the resources and investments are more focused.

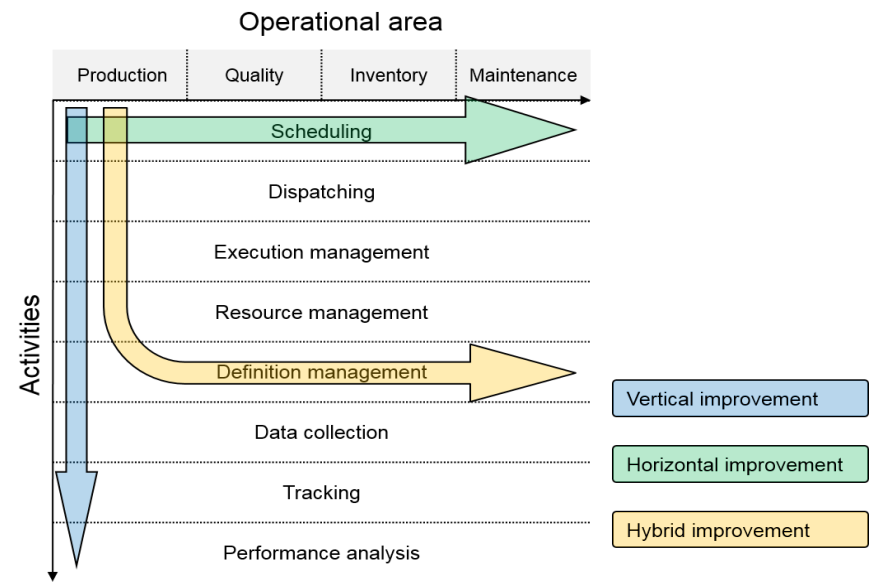

Fig. 1. Different types of improvement strategies

Horizontal improvement strategy focuses on improving maturity levels of a specific activity across operational areas. With this improvement strategy, an enterprise can achieve balanced activity maturity across operational areas so that the enterprise can seek a way to have continuous and simultaneous improvement in all these different operational areas. This strategy takes less time to complete initial maturity evaluation for selected activities. It may, however, require more capital investments as technologies tend to be modularized for each operational area such as scheduling system vs. inventory management system. The advantage can be that the strategy can lead to a more even improvements for the entire organization.

Table 3. Improvement strategies and their tradeoffs

\begin{tabular}{|c|c|c|c|c|}
\hline $\begin{array}{c}\text { Improvement } \\
\text { strategies }\end{array}$ & Focus & $\begin{array}{c}\text { Initial } \\
\text { time needed }\end{array}$ & $\begin{array}{c}\text { Initial capital } \\
\text { investment }\end{array}$ & Positive Effect \\
\hline Vertical & $\begin{array}{c}\text { High priority } \\
\text { operational area }\end{array}$ & Low & Low & High initial ROI \\
\hline
\end{tabular}




\begin{tabular}{|c|c|c|c|l|}
\hline Horizontal & Activity & Low & High & $\begin{array}{l}\text { Balanced factory-wide } \\
\text { improvement }\end{array}$ \\
\hline Hybrid & $\begin{array}{l}\text { Weakest } \\
\text { activities }\end{array}$ & High & Depends & $\begin{array}{l}\text { More balanced factory- } \\
\text { wide improvement }\end{array}$ \\
\hline
\end{tabular}

Hybrid improvement strategy focuses on achieving balanced maturity levels for the entire matrix of activities and operational areas by prioritizing the improvement based on the weakest activity. With this improvement strategy, the enterprise can achieve factory-wide balanced maturity. However, if there are equally weak activities across operational areas or once the maturities across activities are leveled out, the horizontal or vertical strategy must be applied. The drawback is that to use this improvement strategy, a sizable initial effort, larger than those required in the previous two strategies, is needed to evaluate maturity levels of all activities across all operational areas. The capital investment will depend on the variation of the maturities across the matrix.

With evaluation and utilization of different types of strategies, an enterprise can pursue robust and mature manufacturing operations and processes which can yield continuous improvements and effective production. To achieve the goal of optimized manufacturing operations, an enterprise should have evaluated their practices. Fig. 2 shows example evaluation results of a current and an improved status of their practices in their manufacturing operations. As shown in the charts, in current practices, performance analysis (which is denoted as POM/PA) is the weakest activity among 8 activities under the production operations management. The rest of activities are evaluated no higher than level 3. If an enterprise in this example decides to take the vertical improvement strategy, which is to promote maturity levels of all activities under one operational area, the evaluation result would look like the chart noted "After" in Fig. 2. Since level 3 in MESA MOM/CMM is a threshold that all organizations should aim to achieve initially, one would like to pursue a way to promote maturity level of activities evaluated as inferior until they match level 3 requirements before improving other activities already at level 3.

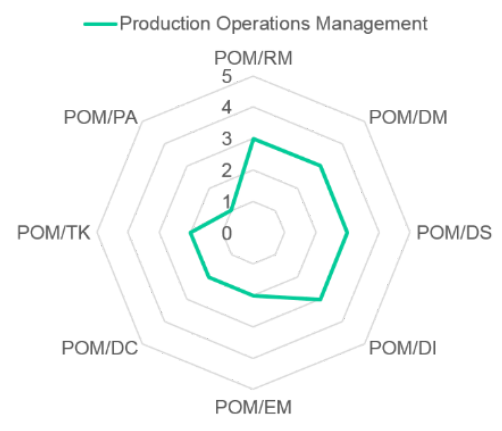

Before

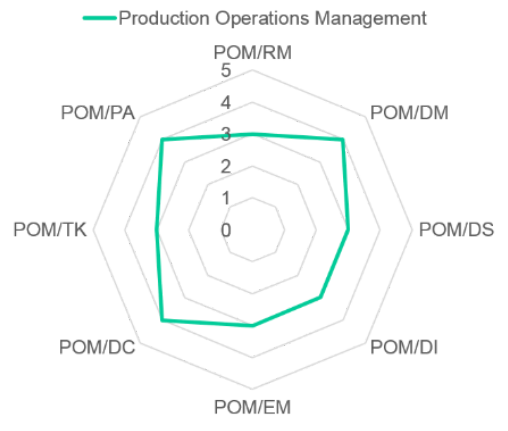

After

Fig. 2. Example evaluation results of current and improved status 


\section{Conclusion and Discussion}

In this research, restructuring of MESA MOM/CMM and manufacturing operations improvement strategies were introduced. By grouping questions and converting them into multiple-choice questions, the number of words and questions included in the original model is reduced considerably. The preservation of the original intent is verified by a successful programmatic translation of answers in the new structure to the original structure. Our future work lies in the validation that the new structure saves time to answer all questions.

Three types of improvement strategies, each of which serve as a guideline for evaluating and improving the manufacturing operations practices, were proposed. With the improvement strategies and new questionnaire structure, a manufacturing enterprise can enhance its planning to complete the evaluation and track and improve its manufacturing operation management maturity, which is foundational to deploying smart manufacturing technologies.

The MESA MOM/CMM is still in its infancy stage, and we are actively working toward piloting the model with real factories. We are also considering further improving the questionnaire - to make it more respondent-friendly. To this end, we will be exploring gamification techniques. Our hypothesis is that gamifying the questionnaire would capture evaluators' interests to complete the questionnaire and reduce the rate of evaluators' drop-off before the completion of the questionnaire.

\section{Reference}

1. H. S. Kang, J. Y. Lee, S. Choi, H. Kim, J. H. Park, J. Y. Son, B. H. Kim and S. D. Noh, "Smart manufacturing: Past research, present findings, and future directions," International Journal of Precision Engineering and Manufacturing - Green Technology, 2016.

2. M. Mcclellan, "The Collaborative Effect," Intelligent enterprises - San Maeo, vol. 7, p. 35,2004 .

3. K. Jung, B. Kulvatyunyou, S. Choi and M. P. Brundage, "An overview of a Smart Manufacturing System Readiness Assessment," in Intl. Conf. on Advances in Production Management Systems, 2016.

4. ANSI/ISA-95.00.01-2013, Enterprise-Control System Integration Part 3: Activity Models of Manufacturing Operations Management.

5. D. Brandl, "MESA MOM Capability Maturity Model Version 1.0," White Paper \#53, MESA International white paper, 2016.

6. ANSI/ISA-95.00.01-2000, Enterprise-Control System Integration Part 1: Models and Terminology.

7. D. He, A. Lobov and J. L. M. Lastra, "ISA - 95 Tool for Enterprise Modeling," in ICONS: The Seventh International Conference on Systems, Saint Gilles, Reunion, France, 2012.

8. K. T. Yeo and Y. Ren, "Risk ManagementCapability Maturity Modelfor Complex ProductSystems (CoPS) Projects," Systems Engineering, vol. 12.4, pp. 275-294, 2009. 
9. M. Mani, K. Lyons and R. Sriram, "Developing a sustainability manufacturing maturity model," in Proceedings from the IMS Summer School on Sustainable Manufacturing, 2010.

10. B. Tucker and J. Paxton, "SCRL-model for Human Space Flight Operations enterprise supply chain," 2010 IEEE Aerospace Conference, pp. 1-9, 2010.

11. OSD Manufacturing Technology Program, "Manufacturing Readiness Level (MRL) Deskbook," $\quad$ May 2011. [Online]. Available: http://www.dodmrl.com/MRL_Deskbook_V2.pdf. [Accessed 14 March 2017].

12. D. A. Dillman, M. D. Sinclair and J. R. Clark, "Effects of questionnaire length, respondent-friendly design, and a difficult question on response rates for occupantaddressed census mail surveys," Public Opinion Quarterly, vol. 57.3, pp. 289-304, 1993.

13. A. N. Oppenheim, Questionnaire design, interviewing and attitude measurement, Bloomsbury Academic, 2000.

14. G. Weems, A. Onwugbuzie and D. Lustig, "Profiles of respondents who respond inconsistently to positively-and negatively-worded items on rating scales," Evaluation \& Research in Education, vol. 2003, pp. 45-60, 2003.

15. D. Brandl, "Business to manufacturing (B2M) collaboration between business and manufacturing using ISA-95," Revue De L Electricite Et De L Electronique 8, pp. 46-52, 2002. 